Nghiên cứu sinh Vũ Vân Nga được tài trỡ bởi Nhà tài trợ thuộc Tập đoàn Vingroup và hỗ trợ bởi chương trình học bổng đào tạo thạc sĩ, tiến sĩ trong nước của Quỹ Đổi mới sáng tạo Vingroup (VINIF), Viện Nghiên cứu Dữ liệu lớn (VinBigdata), mã số VINIF.2020.TS.79.

\section{TÀI LIẸU THAM KHẢO}

1. International Diabetes Federation (2019), IDF Diabetes Atlas Nine edition 2019.

2. Hammoud T và cộng sự(2000). Management of coronary artery disease: therapeutic options in patients with diabetes, Journal of the American College of Cardiology, 36(2):355-65.

3. American Diabetes Association (2020), 2. Classification and Diagnosis of Diabetes: Standards of Medical Care in Diabetes-2020, Journal Diabetes Care, 43(Suppl 1), tr. S14

4. D'Agostino RB, Vasan RS, Pencina MJ, Wolk PA, Cobain M, Massaro JM, Kannel WB(2008), General Cardiovascular Risk Profile for Use in Primary Care The Framingham Heart Study, Circulation,117: 743-753.
5. Detection NCEPEPo, Adults ToHBCi (2002). Third report of the National Cholesterol Education Program (NCEP) Expert Panel on detection, evaluation, and treatment of high blood cholesterol in adults (Adult Treatment Panel III): The Program

6. Oliveira DS, Tannus LRM, Matheus ASM, Correa FH, Cobas R, Cunha EF, Gomes MB(2007), Evaluation of cardiovascular risk according to Framingham criteria in patients with tuýp 2 diabetes,Arquivos Brasileiros de Endocrinologia \& Metabologia, 51(2):268-74.

7. Đố Thi Quỳnh, Vũ Vân Nga, Lê Thi Hòa, Lê Thị Diễm Hồng, Vũ Thị Thớm (2019), Nghiên cứu ứng dung mô hình theo thang điểm Framingham dự đoán nguy cơ mắc bệnh tim mạch 10 năm trên nhóm nhân viên văn phòng tại Hà Nôi. VNU Journal of Science: Medical and Pharmaceutical Science, 35(1):128-136

8. Nguyễn Đức Công, Nguyên Hồng Huệ (2011), Nghiên cứu ước tính nguy cơ bệnh động mach vành trong 10 năm tới theo thang điểm Framingham ở người thừa cân béo. Tạp chí Nghiên cứu Y học, 15(2):45-50

\title{
PHẪU THUẬT NỐI LẠI NGÓN TAY ĐỨT RờI BẰNG KỸ THUÂ̂T VI PHẪU
}

\author{
Hồ Mẫn Trường Phú*, Nguyễn Đặng Huy Nhật*, Lê Khánh Linh*,
} Hồ Văn Nhân*, Phạm Trần Nhật Linh*

\section{TÓM TẮT}

Mục tiêu: Nghiên cứu đặc điểm tổn thương trong đứt rời ngón tay và đánh giá kết của phẫu thuật nối lại ngón tay vi phâu. Đối tượng và phương pháp: 14 bệnh nhân với 32 ngón tay được phẫu thuật nối lại ngón tay bằng kỹ thuật vi phâuu tại BVTW Huế (từ 4/2019 đến tháng 6/2020). Nghiên cứu mô tả tiến cứu có theo dõi các đặc điểm tổn thương ngón tay đứt rời ngón và các đặc điểm chức năng và thẫm mỹ ngón tay sau mổ. Kết quả: 14 bệnh nhân với 32 ngón taybi đứt rời ngón tay được khâu nối vi phẫu, gồm 13 nam và 1 nữ; đô tuổi từ 20 đến 60 tuối; có nhiều nguyên nhân khác nhau, trong đó chiếm đa số là cưa cắt với $50 \%$. Ngón 2 chiếm tỷ lệ nhiều nhất với 9 ngón trong số 32 ngón bị đứt rời. Chiếm đa số là tổn thương tại vùng $\mathrm{V}$ với 15 trường hợp. Có $3 / 32$ ngón có sung huyết tĩnh mạch, 3 trường hợp hoại tử. Thời gian mổ kéo dài tuỳ trường hợp, giới hạn từ 2 đến 9 giờ và trung bình là $4.9 \pm 2.2$ giờ. Theo dõi sau 1 tháng và 3 tháng, không ghi nhân trường hợp nào có rối loan di cảm, đau hay tê rân đầu ngón tay. Tất cả những bệnh nhân được nối ngón tay sau mổ đều bắt đâuu có cảm

*Bênh viên Đa khoa Trung ưng Huế

Chịu trách nhiệm chính: Hồ mần Trường Phú

Email: bsnttrph@yahoo.com

Ngày nhân bài: $12 / 6 / 2021$

Ngày phản biên khoa hoc: 10/7/2021

Ngày duyệt bài: 28/7/2021 giác nông (đau và sờ thô sơ). 20/29 ngón tay được nối ngón vi phẫu đã có cơ năng tương đối tốt, biên độ vân động gần bình thường so với tay bên đối diên. Biến dạng móng và teo búp ngón có xảy ra nhưng không đáng kể. Đa số bênh nhân đều thể hiên hài lòng về mặt thẫm mỹ với ngón tay sau khi được nối lai. Kết luâan: Phẫu thuât nối lai ngón tay bằng kỹ thuật khâu nối vi phẫu đang trở thành lựa chọn chính yếu trong đứt rời ngón tay và chỉ định này càng đước mở rộng hỡn nhờ sự thành thạo về kỹ năng phẩu thuật vi phẫu và sự phát triển vượt bậc của các loại kính vi phâuu thế hệ mới.

Tư khoá: Bàn tay, tạo hình vi phẫu, nối lại ngón tay, đứt rời ngón tay

\section{SUMMARY}

\section{REPLANTATION FOR FINGER AMPUTATION} WITH MICROSURGICAL TECHNIQUE

Objectives: To study the clinical characteristics of finger amputation and to evaluate the outcome of microsurgical finger replantation. Material and method: The study was carried out at Hue Central Hospital (from 4/2019 to 6/2020) on 14 patients with 32 fingers who were surgically reattached by microsurgery. A prospective descriptive study with follow-up on the characteristics of finger amputation and the functional and aesthetic characteristics of the fingers after surgery. Results: 14 patients with 32 severed fingers were replanted with microsurgical technique, including 13 male and 1 female; age from 
20 to 60 years old; There are many different causes, of which the majority is saw cutting with $50 \%$. Finger 2 accounts for the most proportion with 9 fingers out of 32 being severed. Most of the lesions are in zone $V$ with 15 cases. There are 3/32 fingers with venous congestion, 3 cases of necrosis. The length of surgery depends on the case, ranging from 2 to 9 hours and the average is $4.9 \pm 2.2$ hours. After 1 month and 3 months follow-up,there were no cases of paresthesia, pain or numbness in the fingertips. All patients began to have superficial sensations (pain and rudimentary palpation). 20/29 fingers replanted with microsurgery had relatively good function, the range of motion was close to normal compared to the opposite hand.Nail deformity and pulp atrophy occur but are not significant. Almost all patients expressed aesthetic satisfaction with the appearance finger after reattachment. Conclusion: Finger-joint surgery is becoming a key option in finger fracture and the designation is further expanded due to the understanding of microsurgical surgery and the rapid development of microscopic lenses. New-generation surgery and of microsurgery and micro-surgical instruments. Microsurgery finger replantation surgery is becoming the key option for finger severing and this indication is further expanded by proficiency in microsurgery skills and growth beyond level of new generation microscopic.

Key words: Hand, microsurgery reconstruction, finger replantation, finger amputation.

\section{I. ĐẶT VẤN ĐỀ}

Lĩnh vực tạo hình vi phẫu ngày càng phổ biến và đóng một vai trò hết sức quan trọng với hai mục tiêu chính yếu là khôi phục lại sự đầy đủ về mắt chức năng và mang lại sự hài lòng về mă̆t thẫm mỹ. Phẫu thuật nối lại chi được định nghĩ̉a là kết nối, gắn kết lại phần chi bị cắt rời bằng việc tái lập lại các cấu trúc mạch máu, thần kinh và cớ, xương để đat đến sự khôi phục laai chi ban đầu. Trong thực hành lâm sàng, các tổn thương ở vùng bàn tay, ngón tay là rất thường gặp, các tổn thương này có thể xuất hiện ở bất cứ vùng nào ở bàn tay hoặc ngón tay, cấu trúc bị tổn thương có thể là phức hợp gồm xương, khớp, gân và mô mềm. Đứt rời ngón tay là một tổn thương rất nặng nề về măt xã hội, bởi nó ảnh hưởng đến khả năng kiếm sống, giúp đỡ gia đình, và thậm chí là thực hiện các hoạt động sinh hoạt thông thường của bệnh nhân. Nó cũng gây tổn hại rất lớn về mặt tâm lý cho bệnh nhân.Có rất nhiều những phương án để tái tạo khuyết hống để lại trong những trường hợp này, bao gồm cả việc chuyển vạt che phủ. Tuy nhiên, nếu hệ mạch máu phần đứt rời thích hợp để thực hiện miệng nối, thì nối lại ngón tay, bàn tay vi phẫu là một lựa chọn tối ưu hớn so với các kỹ thuật khác. Kể từ ca nối lại chi đầu tiên được báo cáo bởi Komatsu và Tamai năm 1968, hàng ngàn ca ngón tay và các phần cơ thể đã được cứu thành công nhờ phẫu thuật nối lại. Mục tiêu của phẫu thuât nối lại chi sau đứt rời do chấn thương là cứu sống phần chi đó cả về hình thể và chức năng [1]. Có rất nhiều yếu tố phối hợp để cân nhắc đưa ra quyết định phẫu thuật nối lại: tầm quan trọng của phần đứt rời, mức độ tổn thương, cơ chế chấn thương, chức năng mong muốn hồi phục... Vì vậy, trong nghiên cứu này, chúng tôi thực hiện phâu thuật nối lại ngón tay bằng kỹ thuật vi phẫu cho 14 bệnh nhân đứt rời ngón tay do nhiều nguyên nhân khác nhau nhằm đánh giá đặc điểm tổn thương trong đứt rời ngón tay và đánh giá kết của phẫu thuật nối lại ngón tay vi phẫu.

\section{II. ĐỐI TƯợNG VÀ PHƯƠNG PHÁP NGHIÊN CỨU}

2.1. Đối tượng: Gồm 14 bệnh nhân bị đứt rời 32 ngón tay, được phẫu thuật cấp cứu nối lại ngón bằng kỹ thuật khâu nối vì phâuu từ tháng 4/2019 đến tháng 6/2020.

\subsubsection{Tiêu chuẩn chọn bệnh}

- Đứt rời ngón tay đến sớm $<18 \mathrm{~h}$

- Bênh nhân không có bênh lý mạch máu

- Phần đút rời không quá dập nát, đứt nhiều đoạn

\subsubsection{Tiêu chuấn loại trừ}

- Bệnh nhân sốc chấn thương, chấn thương sọ não nặng...

- Tổn thương dập nát nặng, nhiều đoạn.

- Bệnh nhân khồng đồng ý nối lại.

2.2. Kỹ thuật: Bệnh nhân được vô cảm bằng gây tê đám rối hoặc gây mê toàn thân.

2.2.1. Chuẩn bị phân ngón đứt rời: Việc chuẩn bị phần ngón đứt rời được thực hiện trước khi vô cảm hoặc thậm chí trước khi chuyển lên phòng mổ.Mạch máu và thần kinh mặt gan tay được bộc lộ, bơm rửa bằng heparin, khâu đánh dấu bằng chỉ Nylon 10/0. Xương được làm sạch, cắt gọn và xuyên 2 đinh Kirchner trong - ngoài. Gân sẽ được khâu giữ bằng chỉ Prolene 4/0.

2.2.2. Chuẩn bị phân mỏm cụt: Xương sẽ được cắt gọn, cấu trúc mạch máu và thần kinh được phẫu tích và được đánh dấu bằng mực hoắc chỉ Prolene 10/0. Mach máu được bơm rửa bằng heparin. Đầu gần gẩn được tìm và khâu giữ bằng chỉ $4 / 0$.

2.2.3. Cố định xương: Đinh Kirchner được sử dụng để xuyên trong - ngoài vào phần ngón đứt rời và tiếp tục xuyên ngược lại qua đầu gần ngón tay.

2.2.4. Thì mă̆t gan tay: Khâu nối các thành phần theo thứ tự sau

+ Khâu nối gân : Nếu đứt rời ngón vùng 1 và vùng 2 thì chỉ cần khâu gân gấp sâu. Gân được 
khâu nối bẳng chỉ Prolene 4.0 và tăng cường bằng Prolene 6.0. Đứt rời ở vùng 3 , cả gân gấp nông và sâu đều được khâu nối.

+ Khâu nối thần kinh: Có thể thực hiên trước hoăcc sau khâu nối mach máu. Khẩu thần kinh bằng chỉ Nylon 9/0 hoặc 10/0.

+ Khâu nối động mạch: Động mạch có thể được khâu nối trực tiếp hoặc cần ghép tĩnh mach khi bị mất đoạn. Có thể nối một hoặc cả hai động mạch ngón tay.

\subsubsection{Thì mă̆t mu tay}

+ Khâu nối gẩn duỗi: Vùng 1 và 2, gân được khâu mũi chữ $U$ bằng Prolene $4 / 0$. Đứt gân vùng 3, khâu 2 trẽ bên để vận động khớp.

+ Khâu nối tĩnh mạch: Tĩnh mạch được khâu nối trực tiếp hoặc được ghép bằng tĩnh mạch ở cổ tay. Tĩnh mạch được khâu nối bằng chỉ Prolene 10/0.

2.2.6. Đóng da: Có thể khâu đóng trực tiếp, ghép da hoặc các loại vạt khác nhau để che phủ khuyết hỗng.

2.2.7. Chăm sóc và theo dõi:Bệnh nhân được theo dõi tình trạng tưới máu phần ngón được nối lại, tính trạng vết mổ. Khi có bẳng chứng của liền xương thì đinh Kirchner được rút, thường sau 6-8 tuần, sau đó tập phục hồi chức năng ngón tay nhẹ nhàng. Sau 1-3 tháng, đánh giá cảm giác thô sớ và các biểu hiện dị cảm ngón tay; đánh giá chức năng vận động ngón tay về vận động thụ động và chủ động.

\section{KẾT QUẢ NGHIÊN CỨU}

Theo kết quả bảng 1 , các bệnh nhân có độ tuổi từ 20 đến 63 tuối (trung bình $39.9 \pm 14.3$ ), chủ yếu là nam giới (92.9\%). Nguyên nhân do các vật sắc gọn như bị chém và dao cắt $(42.8 \%)$, cưa cắt $(50 \%)$, tai nạn giao thông (7.2\%). Tỷ lệ giữa tay phải và trái là tương đương nhau, lần lượt là $42.9 \%$ và $57.1 \%$.Có 5 trường hợp $(35.7 \%)$ là đứt rời từ ba ngón trở lên, 3 trường hợp đứt rời hai ngón và 6 trường hợp chỉ một ngón. Về loại ngón tay bị ảnh hưởng, ngón 2 chiếm đa số (28\%).Phần lớn tổn thương taii vùng $V(15 / 32)$. Thời gian từ lúc bảo quản ngón đến khi được nối trung bình: $4.4 \pm$ 2.2 giờ. Thời gian mổ trung bình: $4.9 \pm 2.2$ giờ.

Bảng 1. Mốt số đặc điểm chung

\begin{tabular}{|c|c|c|c|}
\hline \multicolumn{2}{|c|}{ Đặc điểm chung } & $\mathbf{N}$ & $\mathbf{\%}$ \\
\hline \multirow{3}{*}{$\begin{array}{c}\text { Nguyên } \\
\text { nhân }\end{array}$} & Bị chém & 3 & 21.4 \\
\cline { 2 - 4 } & Dao cắt & 3 & 21.4 \\
\cline { 2 - 4 } & Bị cưa cắt & 7 & 50 \\
\cline { 2 - 4 } Bên tay & TNGT & 1 & 7.2 \\
\cline { 2 - 4 } & Phái & 6 & 42.9 \\
\cline { 2 - 4 } & Trái & 8 & 57.1 \\
\hline
\end{tabular}

\begin{tabular}{|c|c|c|c|}
\hline \multirow{4}{*}{ Vị trí } & Ngón 1 & 5(ngón) & 15.6 \\
\cline { 2 - 4 } ngón & Ngón 2 & 9 & 28.0 \\
\cline { 2 - 4 } & Ngón 3 & 6 & 18.8 \\
\cline { 2 - 4 } & Ngón 4 & 6 & 18.8 \\
\cline { 2 - 4 } & Ngón 5 & 6 & 18.8 \\
\hline \multirow{4}{*}{ Chỉ địnhn } & Ngón cái & 3 & 21.4 \\
\cline { 2 - 4 } & $\geq 3$ ngón & 5 & 35.7 \\
\cline { 2 - 4 } & Vết thương sắc gộn & 2 & 14.3 \\
\cline { 2 - 4 } & Bệnh nhân yêuu cầu & 4 & 28.6 \\
\hline
\end{tabular}

Theo kết quả bảng 2, không ghi nhận trường hợp nào nhiễm trùng sau mổ, bệnh nhân ít đau sau mổ, chỉ sử dụng thuốc giảm đau thông thường. Có $3 / 32$ ngón tay có sung huyết tĩnh mạch, được theo dỗi và duy trì Lovenox kéo dài hởn, rút móng giảm căng, sau đó có 1 ngón bị hoại tử, 2 ngón còn lại tự hồi phục.

Bảng 2. Đánh giá kêt quả sau mô

\begin{tabular}{|c|c|c|c|}
\hline \multicolumn{2}{|c|}{ Theo dõ̃i sau mố } & $\mathbf{N}$ & $\mathbf{\%}$ \\
\hline \multicolumn{2}{|c|}{ Đau sau mố } & 0 & 0 \\
\hline \multirow{2}{|c|}{ Nhiêm trùng } & 0 & 0 \\
\hline \multirow{2}{*}{$\begin{array}{c}\text { Sung } \\
\text { huyết }\end{array}$} & Có & 3 & 9.4 \\
\cline { 2 - 4 } Hoại tử & Không & 29 & 90.6 \\
\cline { 2 - 4 } & Có & 3 & 9.4 \\
\cline { 2 - 4 } & Không & 29 & 90.6 \\
\hline
\end{tabular}

Tất cả các ngón tay sau khâu nối đều bắt đầu có cảm giác thố sơ trở lại sau 1 tháng và chậm nhất là 3 tháng. Có 9 ngón tay có giới hạn cả gấp và duỗi ngón tay ở hai bệnh nhân đứt rời 4 và 5 ngón tay vùng $V$. Có $20 / 29$ ngón tay còn sống đã có cơ năng tốt, biên độ vận động gần bình thường so với tay bên đối diện.Không ghi nhận trường hợp nào có rối loạn dị cảm, đau do u, sẹo thần kinh (bảng 3).

Bảng 3. Đánh giá phục hồi cảm giácsớm sau mổ 3 tháng

\begin{tabular}{|c|c|c|c|}
\hline Sau 1 tháng và 3 tháng & $\mathbf{N}(\mathbf{2 9})$ & $\mathbf{\%}$ \\
\hline Dị cảm ngón & Có & 0 & 0 \\
\cline { 2 - 4 } tay & Không & 29 & 100 \\
\hline Có cảm giác & Có & 29 & 100 \\
\cline { 2 - 4 } thô sớ & Không & 0 & 0 \\
\hline Vận động & Giới hạn & 9 & 31 \\
\cline { 2 - 4 } ngón tay & Không giới hạn & 20 & 69 \\
\hline
\end{tabular}

Về biễn chứng, có 3 trường hợp hoại tử ngón tay sau khâu nối, gồm 1 ngón là do sung huyết không hồi phục, còn 2 ngón còn lại ở trên cùng một bệnh nhân lớn tuổi, mạch máu xơ vữa nhiều và tổn thương là do cưa nên giằng xé nhiều, gây tắc mạch sớm sau mổ

\section{BÀN LUÂN}

Việc chỉ định phẫu thuật nối lại ngón tay trong đứt rời được chỉ định rất khác nhau dựa vào ngón bị tổn thương, vị trí tổn thương, số ngón, mức độ, nguyên nhân và thậm chí là 
mong muốn của bệnh nhân để đảm bảo thẫm mỹ bàn tay.

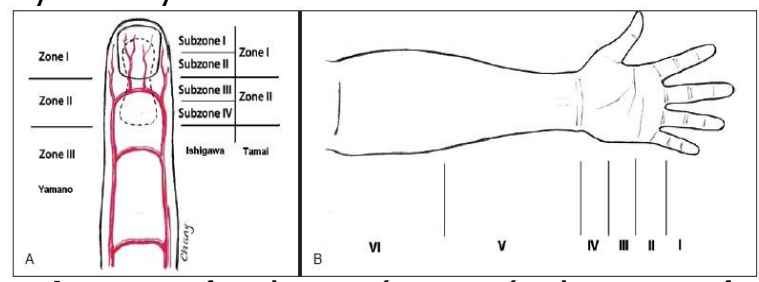

Hình 1. Phân vùng ngón tay đút rời được khâu nối theo Ishigawa và Tamai

Hiện nay, đa số các tác giả sử dụng bảng phân loại đứt rời ngón tay theo Ishigawa và Tamai [2] với 5 vùng từ vùng $I$ đến vùng $V$ (hình $1)$, vị trí đứt rời càng gần đầu ngón thì càng ít ảnh hưởng đến chức năng ngón tay.Nhờ sự phát triển của mảng vi phẫu, với sự tiến bộ về thiết bị phóng đại lớn, độ phân giả cao kèm dụng cụ vi phẫu ngày càng tinh vi thì chỉ định nối ngón, đặc biệt ở vùng xa ngón tay (vùng I, II) cũng được mở rộng nhiêu hơn trước đây [7]. Nối lại ngón cái gần như là chỉ định tuyệt đối do chiếm đến $40 \%$ chức năng của bàn tay [6]. Về số ngón, khi đứt rời 3 ngón trở lên thì ưu tiên nối lại tất cả số ngón bị cắt rời do mỗi ngón được nối lại đều có sự suy giảm chức năng với bình thường. Về mức độ, vết thương sắc gọn là một chỉ định tốt cho nối ngón, các tổn thương cùn, giằng xé không tốt cho chỉ định nối ngón. Mặc dù sự hồi phục sau mổ trong những trường hợp này là không mong đợi cho dù ngón tay sống, tuy nhiên mong muốn của bệnh nhân là rất lớn vì đa số tổn thương này hay gặp ở nữ [2][4]. Về phương tiện kết hợp xương ngón tay, chúng tôi cố định xương bằng đinh Kirchner vì tiện lợi, nhanh chóng, tiết kiệm thời gian, dễ thực hiện. Rút đinh $\mathrm{K}$ sau 6 tuần và tập phục hồi chức năng.

Mục tiêu hàng đầu của nối lại ngón tay là cứu sống ngón tay và đem lại chức năng mong đợi [1]. Vậy nên, sửa chữa gân và thần kinh ngay trong một thì nối ngón được ưu tiên. Sẹo phì đại ở vùng mổ là một bằng chứng mạnh mẽ cho việc nỗ lực tái tạo toàn bộ một thì, tránh việc mổ lại lần hai [3]. Trong nghiên cứu của chúng tôi, gân gấp và gân duỗi đều được khâu nối ngay thì đầu và hiệu quả đến $69 \%$ trường hợp có cơ năng tốt. Khâu phục hồi thần kinh chính xác thì đầu là thật cần thiết, bởi vì sự thành công của ngón tay được cứu sống phụ thuộc vào phần lớn ngón tay được phục hồi cảm giác. Chúng tôi đều thực hiện ít nhất là một miệng nối thần kinh gian ngón tay, vì vậy không có trường hợp nào mất cảm giác sau mổ và không có trường hợp nào dị cảm hoặc đau do u thần kinh nhờ miệng nối thực hiện chính xác và khâu chỉ Prolene 10.0 dưới kính vi phẫu có độ phóng đại lớn. Mặc dù miệng nối động mạch quyết định sự sống của ngón tay, tuy nhiên phục hồi lưu lượng tĩnh mạch về giúp tránh sung huyết và ứ trệ máu cũng cần phải quan tâm [5]. Việc khâu nổi tránh gây căng, nếu cần có thể dùng tĩnh mạch ở vùng cổ tay để ghép. Trong 3 trường hợp sung huyết sau mổ là do ứ trệ muộn tĩnh mạch, bệnh nhân được xử trí kê cao tay, cắt bớt chỉ, duy trì liều Lovenox kéo dài ra, rút móng tay chống căng đã cứu được 2 ngón tay, còn 1 ngón không cứu được và bị hoại tử. Tỷ lệ nối ngón tay thành công được cải thiện rất nhiều nhờ sự phát triển của kỹ thuật vi phẫu, dao động từ $60-94 \%$ tuỳ thuộc vào cơ sở thực hiện. Tỷ lệ nối ngón thành công của chúng tôi là $90.6 \%$ và tỷ lệ phục hồi chức nănglà 69 \%.

\section{KẾT LUÂ̂N}

Chỉ định phẫu thuật nối lại ngón tay vi phẫu đang trở thành lựa chọn chính yếu trong đứt rời ngón tay và ngày càng được mở rộng hơn.Đây là một kỹ thuật đòi hỏi phẫu thuật viên phải được đạo tạo bài bản, kỹ năng khéo léo và tính kiển nhẫn cao. Mục tiêu của bài báo không phải tập trung về mô tả kỹ thuật mà thông qua kết quả khả quan của nghiên cứu, chúng tôi muốn nhấn mạnh đến tính cấp thiết cần phải phục hồi chức năng của các ngón tay, nâng cao tính thẫm mỹ và đáp ứng tâm lý hài lòng của bệnh nhân.

\section{TÀI LIẸU THAM KHẢO}

1. Venkatramani .H, Sabapathy .S .R, (2011), "Fingertip replantation: Technical considerations and outcome analysis of 24 consecutive fingertip replantations". Indian J Plast Surg; 44(2):237-245.

2. Yoshimura, .M, (2003), "Indications andLimits of Digital Replantation".' Journal of the Japan Medical Association; 46(10): 460-467.

3. Weiland . A .J, Villarreal-Rios .A, Kleinert .H .E, Kutz J, et all, (1977), "Replantation of digits and hands: analysis of surgical techniques and functional results in 71 patients with 86 replantations". J Hand Surg Am; 2(1):1-12.

4. Molski .M, (2007), "Replantation of fingers and hands after avulsion and crush injuries". J Plast Reconstr Aesthet Surg;60(7):748-754.

5. Hattori .Y, Doi .K, Ikeda .K, et all, (2003), "Significance of venous anastomosis in fingertip replantation". Surg;111(3):1151-1158.

6. Motamedolshariati .M.S, Rezaei .E, Dahmardehei . M, (2015), "Finger Replantation: A Review of Replantation of Four Fingers in Three Patients". Zahedan J Res Med Sci; 17(1): 47-50.

7. An-shi .H, Subhash .R, Jia-xiang .G et al, (2016), "Fingertip replantation (zone I) without venous anastomosis: clinicalexperience and outcome analysis". SpringerPlus; 5:1835. 